\title{
Correlation between inflammatory factors and post-stroke pneumonia in diabetic patients
}

\author{
HONGMING ZHANG and XIAOYAN LI \\ Department of Cardiology, The General Hospital of Jinan Military Region, Jinan, Shandong 250031, P.R. China
}

Received January 28, 2013; Accepted April 19, 2013

DOI: $10.3892 / \mathrm{etm} .2013 .1103$

\begin{abstract}
Pneumonia is the most common cause of mortality in stroke patients and it has been demonstrated to contribute to mortality and poor functional outcome following stroke in the majority of clinical studies. The risk of infection may be attributed to stroke-induced immunodepression syndrome (SIDS). Cytokine production is increased in SIDS. However, the correlation between biomarkers and the risk of post-stroke pneumonia in patients with diabetes mellitus is not clear. The aim of this study was to determine the correlation between pneumonia and the levels of C-reactive protein (CRP) and interleukin-6 (IL-6), as well as to identify early predictors of pneumonia in acute ischemic stroke patients with diabetes mellitus. Additionally, we investigated the impact of pneumonia on functional outcome after 1 month. A total of 106 ischemic stroke patients with diabetes mellitus who were admitted after the onset of symptoms were included in the study. They were divided into two groups, the pneumonia and non-pneumonia groups. CRP, IL-6, white blood cells (WBCs), mean body temperature and National Institutes of Health Stroke Scale (NIHSS) score were measured at the time of admission. The modified Rankin Scale score was assessed at 30 days. The levels of IL-6, CRP and WBCs, as well as mean body temperature were significantly higher in the patients with pneumonia than in the patients without pneumonia. There were also significant differences between the pneumonia and non-pneumonia groups in age, admission NIHSS score, length of hospital stay and dysphagia. Pneumonia patients had worse outcomes compared with patients without pneumonia at 1 month. Age, NIHSS score and dysphagia were significantly associated with pneumonia. WBCs and mean body temperature were not significant predictors of pneumonia. Older patients with more severe ischemic stroke are more susceptible
\end{abstract}

Correspondence to: Dr Hongming Zhang or Dr Xiaoyan Li, Department of Cardiology, The General Hospital of Jinan Military Region. 25 Shifan Road, Tianqiao, Jinan, Shandong 250031, P.R. China

E-mail: hongmingzhang1@sina.com

E-mail: lixiaoyan1@126.com

Key words: acute ischemic stroke, C-reactive protein, interleukin-6, pneumonia, diabetes mellitus to the development of pneumonia during the stay in hospital. Pneumonia contributes to poor functional outcome. IL-6, CRP, age, NIHSS score and dysphagia may predict the occurrence of pneumonia on the day of stroke symptom onset.

\section{Introduction}

Pneumonia is a common cause of mortality in stroke patients (1-8). The risk of infection may be attributed to stroke-induced immunodepression syndrome (SIDS). SIDS is characterized by a loss of lymphocytes, cytokine production, reduced monocyte count and function, and interferon- $\gamma$ deficiency. These effects are associated with pneumonia following stroke $(9,10)$. Biomarkers may facilitate an early diagnosis of pneumonia in patients with acute ischemic stroke (11).

The correlation between biomarkers in acute ischemic stroke with diabetes mellitus, and the risk of pneumonia is not clear. The aim of this study was to determine the correlation between pneumonia and the levels of C-reactive protein (CRP) and interleukin-6 (IL-6), as well as to identify early predictors of pneumonia in acute ischemic stroke patients with diabetes mellitus and the effect of pneumonia on functional outcome after 1 month.

\section{Patients and methods}

Patients. Data for this study were obtained from the General Hospital of Jinan Military Region (Shandong, China). Records were collected from all ischemic stroke patients with diabetes mellitus from July 2009 to September 2012. Patients were excluded from the study if they: i) had an upper respiratory tract infection, ii) had a urinary system infection or iii) were immunocompromized by chemotherapy. Patients were defined as diabetic if they had known diabetes mellitus prior to the stroke, according to the diagnostic criteria of the Expert Committee on the Diagnosis and Classification of Diabetes Mellitus (12). The presence of pneumonia was determined using the Mann criteria of pneumonia (13). The study was approved by the ethics committee of the General Hospital of Jinan Military Region and written informed consent was obtained from each of the participants.

Assessment. At admission, a computed tomography (CT) scan was performed to rule out hemorrhage. White blood cell (WBC), CRP and IL-6 levels were measured on day 1 along 
Table I. Baseline characteristics of the study population.

\begin{tabular}{lccc}
\hline Characteristic & Non-pneumonia group $(\mathrm{n}=74)$ & Pneumonia group $(\mathrm{n}=32)$ & P-value \\
\hline Age (years) & $68.85 \pm 2.40$ & $73.71 \pm 6.30$ & 18 \\
Hypertension & 23 & 10 & $\mathrm{NS}$ \\
Metabolic syndrome & 16 & 11 & $\mathrm{NS}$ \\
Coronary artery disease & 15 & $14.50 \pm 0.6$ & $\mathrm{NS}$ \\
Admission NIHSS score & $9.6 \pm 0.7$ & 11 & $<0.0001$ \\
Dysphagia & 9 & $19.3 \pm 3.2$ & $<0.0001$ \\
Length of hospital stay (days) & $10.2 \pm 0.5$ & $<0.0001$
\end{tabular}

Data presented are mean \pm SD. NIHSS, National Institutes of Health Stroke Scale; NS, no significance.

Table II. Markers of infection.

\begin{tabular}{lccc}
\hline Marker & Non-pneumonia group & Pneumonia group & P-value \\
\hline Interleukin-6 $(\mathrm{pg} / \mathrm{ml})$ & $9.2 \pm 1.6$ & $27.1 \pm 4.3$ & $<0.0001$ \\
C-reactive protein $(\mathrm{mg} / \mathrm{l})$ & $13.4 \pm 3.5$ & $48.4 \pm 10.4$ & $<0.0001$ \\
White blood cells $(\mathrm{Gpt} / \mathrm{l})$ & $8.3 \pm 0.8$ & $12.9 \pm 1.7$ & 0.034 \\
Mean temperature $\left({ }^{\circ} \mathrm{C}\right)$ & $36.7 \pm 0.1$ & $38.4 \pm 0.2$ & $<0.0001$ \\
\hline
\end{tabular}

Data presented are mean $\pm \mathrm{SD} . \mathrm{Gpt}, \times 10^{9}$.

with the mean body temperature. The IL-6 and CRP levels were measured by chemical luminescence immunoassay and WBC levels by electrical impedance.

The National Institutes of Health Stroke Scale (NIHSS) score of each patient was assessed by a neurologist. Functional outcome was assessed at 30 days using the modified Rankin Scale (mRS). Poor outcome was defined as mortality or moderate or severe disability (mRS score, 3-6).

Statistical analysis. Differences in patient characteristics and clinical variables in the pneumonia and non-pneumonia groups were analyzed using the $\chi^{2}$ test and t-test for continuous variables, respectively. The logistic multiple regression model was used to analyze risk factors and pneumonia. Data analyses were performed with commercially available statistical software (SPSS version 11.0; SPSS, Inc., Chicago, IL, USA). P<0.05 was considered to indicate a statistically significant difference.

\section{Results}

The clinical characteristics of stroke patients with and without pneumonia are compared in Table I. Patients with pneumonia were significantly older than those without pneumonia. There were also significant differences between the pneumonia and non-pneumonia groups in admission NIHSS score, length of hospital stay and dysphagia. The rates of hypertension, metabolic syndrome and coronary artery disease were, however, similar in the two groups.

The serum levels of IL-6, CRP and WBCs, as well as mean body temperature in the patients with and without pneumonia are presented in Table II. The levels of IL-6, CRP and WBCs,
Table III. Functional outcome at 30 days.

\begin{tabular}{lccc}
\hline mRS score & $\begin{array}{c}\text { Non-pneumonia } \\
\text { group }\end{array}$ & $\begin{array}{c}\text { Pneumonia } \\
\text { group }\end{array}$ & P-value \\
\hline $0-2$ & 48 & 7 & $<0.0001$ \\
$3-6$ & 24 & 25 & $<0.0001$ \\
\hline
\end{tabular}

mRS, modified Rankin Scale.

Table IV. Predictors for pneumonia.

\begin{tabular}{lll}
\hline Variable & OR $(95 \% \mathrm{CI})$ & P-value \\
\hline Age (years) & $1.66(1.11-1.81)$ & $<0.021$ \\
NIHSS score & $1.36(1.14-1.62)$ & $<0.0001$ \\
C-reactive protein $(\mathrm{mg} / \mathrm{l})$ & $1.54(1.22-1.73)$ & $<0.042$ \\
Interleukin-6 $(\mathrm{pg} / \mathrm{ml})$ & $36.6(2.7-582.6)$ & $<0.001$ \\
White blood cells $(\mathrm{Gpt} / \mathrm{l})$ & $26.5(1.9-362.0)$ & $>0.05$ \\
Mean temperature $\left({ }^{\circ} \mathrm{C}\right)$ & $21.2(2.4-221.3)$ & $>0.05$
\end{tabular}

OR, odds ratio; CI, confidence interval; NIHSS, National Institutes of Health Stroke Scale.

and the mean body temperature were significantly higher in the pneumonia group than in the non-pneumonia group.

The functional outcomes of the ischemic stroke patients with and without pneumonia after 1 month are shown in 
Table III. Pneumonia patients had worse outcomes than patients without pneumonia at 1 month. There were more patients with severe disability (mRS score, 3-6) in the pneumonia group than in the non-pneumonia group.

The risks for pneumonia are shown in Table IV. Age, NIHSS score, IL-6, CRP and dysphagia were significantly associated with pneumonia. WBC level and mean body temperature were not significant predictors of pneumonia.

\section{Discussion}

The rate of pneumonia in this study was $30.2 \%$, which is higher than that reported by previous studies (14-17). Since the subjects were all ischemic stroke patients with diabetes mellitus, this may indicate that subjects with diabetes are more prone to infection. However, a patient sample size of 106 may have been too small to identify a reliable rate of pneumonia.

The current study demonstrates the increased risk of pneumonia following ischemic infarction for older patients with a more severe stroke. Pneumonia increases the length of hospital stay. IL-6 and CRP levels were significantly associated with pneumonia. Additionally, pneumonia had a detrimental impact on outcome 1 month after stroke.

Previous studies have examined the risk factors for infection (5,18-22) These risk factors include greater stroke severity on admission, total anterior circulation infarction, Barthel Index $<5$, Glasgow Coma Scale score $<9$, infarction in the territory of the middle cerebral artery, increased age, current atrial fibrillation, tube feeding and a history of congestive heart failure. Amelioration of neurological impairment and prevention of complications are major goals of stroke treatment. However, conservative measures provide limited protection against post-stroke pneumonia; this raises the possibility that stroke-induced alteration of the systemic immune response is significant.

The current study shows that the risk factors for pneumonia are age, NIHSS, dysphagia, IL-6 and CRP. SIDS may be responsible for the increases in the levels of IL-6 and CRP. Therefore, modulating cytokines and the immune system may be a new treatment strategy for acute ischemic stroke with pneumonia (23).

The correlation between infection risk and more severe ischemic infarctions defined by higher NIHSS score on admission has been established (24-27). Several randomized trials have demonstrated a reduction of the infection rate in stroke patients by prophylactic administration of antibiotics (28-31). The early initiation of antibiotic treatment in older patients with severe ischemic stroke should be considered to improve the clinical outcome.

In conclusion, patients with more severe ischemic stroke and increased age are more susceptible to the development of pneumonia during their stay in hospital. Pneumonia contributes to poor functional outcome. IL-6, CRP, age, NIHSS score and dysphagia may be predictive factors for the occurrence of pneumonia on the day of stroke symptom onset.

\section{References}

1. Hong KS, Kang DW, Koo JS, et al: Impact of neurological and medical complications on 3-month outcomes in acute ischaemic stroke. Eur J Neurol 15: 1324-1331, 2008.
2. Johnston KC, Li JY, Lyden PD, et al; RANTTAS Investigators: Medical and neurological complications of ischemic stroke: experience from the RANTTAS trial. Stroke 29: 447-453, 1998.

3. Katzan IL, Cebul RD, Husak SH, Dawson NV and Baker DW: The effect of pneumonia on mortality among patients hospitalized for acute stroke. Neurology 60: 620-625, 2003.

4. Langhorne P, Stott DJ, Robertson L, et al: Medical complications after stroke: a multicenter study. Stroke 31: 1223-1229, 2000.

5. Ovbiagele B, Hills NK, Saver JL and Johnston SC; California Acute Stroke Prototype Registry Investigators: Frequency and determinants of pneumonia and urinary tract infection during stroke hospitalization. J Stroke Cerebrovasc Dis 15: 209-213, 2006.

6. Tirschwell DL, Kukull WA and Longstreth WT Jr: Medical complications of ischemic stroke and length of hospital stay: experience in Seattle, Washington. J Stroke Cerebrovasc Dis 8: 336-343, 1999.

7. Davenport RJ, Dennis MS, Wellwood I and Warlow CP: Complications after acute stroke. Stroke 27: 415-420, 1996.

8. Sellars C, Bowie L, Bagg J, et al: Risk factors for chest infection in acute stroke: a prospective cohort study. Stroke 38: 2284-2291, 2007.

9. Dirnagl U, Klehmet J, Braun JS, et al: Stroke-induced immunodepression: experimental evidence and clinical relevance. Stroke 38 (Suppl 2): 770-773, 2007.

10. Chamorro A, Urra $X$ and Planas AM: Infection after acute ischemic stroke: a manifestation of brain-induced immunodepression. Stroke 38: 1097-1103, 2007.

11. Gonsalves MD and Sakr Y: Early identification of sepsis. Curr Infect Dis Rep 12: 329-335, 2010.

12. No authors listed: Stroke - 1989. Recommendations on stroke prevention, diagnosis, and therapy. Report of the WHO Task Force on Stroke and other Cerebrovascular Disorders. Stroke 20: 1407-1431, 1989.

13. Mann G, Hankey GJ and Cameron D: Swallowing function after stroke: prognosis and prognostic factors at 6 months. Stroke 30: 744-748, 1999.

14. Vermeij FH, Scholte op Reimer WJ, de Man P, et al; Netherlands Stroke Survey Investigators: Stroke-associated infection is an independent risk factor for poor outcome after acute ischemic stroke: data from the Netherlands Stroke Survey. Cerebrovasc Dis 27: 465-471, 2009.

15. Heuschmann PU, Kolominsky-Rabas PL, Misselwitz B, et al; German Stroke Registers Study Group: Predictors of in-hospital mortality and attributable risks of death after ischemic stroke: the German Stroke Registers Study Group. Arch Intern Med 164: 1761-1768, 2004

16. Hilker R, Poetter C, Findeisen N, et al: Nosocomial pneumonia after acute stroke: implications for neurological intensive care medicine. Stroke 34: 975-981, 2003.

17. Walter U, Knoblich R, Steinhagen V, Donat M, Benecke R and Kloth A: Predictors of pneumonia in acute stroke patients admitted to a neurological intensive care unit. J Neurol 254: 1323-1329, 2007.

18. Kammersgaard LP, Jørgensen HS, Reith J, et al: Early infection and prognosis after acute stroke: the Copenhagen Stroke Study. J Stroke Cerebrovasc Dis 10: 217-221, 2001.

19. Hamidon BB, Raymond AA, Norlinah MI and Jefferelli SB: The predictors of early infection after an acute ischaemic stroke. Singapore Med J 44: 344-346, 2003.

20. Pittock SJ, Meldrum D, Hardiman O, Thornton J, Brennan P and Moroney JT: The Oxfordshire Community Stroke Project classification: correlation with imaging, associated complications, and prediction of outcome in acute ischemic stroke. J Stroke Cerebrovasc Dis 12: 1-7, 2003.

21. Kwan $\mathbf{J}$ and Hand P: Infection after acute stroke is associated with poor short-term outcome. Acta Neurol Scand 115: 331-338, 2007.

22. Vargas M, Horcajada JP, Obach V, et al: Clinical consequences of infection in patients with acute stroke: is it prime time for further antibiotic trials? Stroke 37: 461-465, 2006.

23. Emsley HC and Hopkins SJ. Acute ischaemic stroke and infection: recent and emerging concepts. Lancet Neurol 7: 341-353, 2008.

24. Chamorro A, Amaro S, Vargas M, et al: Interleukin 10, monocytes and increased risk of early infection in ischaemic stroke. J Neurol Neurosurg Psychiatry 77: 1279-1281, 2006.

25. Hug A, Dalpke A, Wieczorek N, et al: Infarct volume is a major determiner of post-stroke immune cell function and susceptibility to infection. Stroke 40: 3226-3232, 2009. 
26. Liesz A, Hagmann S, Zschoche C, et al: The spectrum of systemic immune alterations after murine focal ischemia: immunodepression versus immunomodulation. Stroke 40: 2849-2858, 2009.

27. Chamorro A, Amaro S, Vargas M, et al: Catecholamines, infection, and death in acute ischemic stroke. J Neurolog Sci 252: 29-35, 2007.

28. Schwarz S, Al-Shajlawi F, Sick C, Meairs S and Hennerici MG: Effects of prophylactic antibiotic therapy with mezlocillin plus sulbactam on the incidence and height of fever after severe acute ischemic stroke: the Mannheim infection in stroke study (MISS). Stroke 39: 1220-1227, 2008.
29. Harms H, Prass K, Meisel C, Klehmet J, et al: Preventive antibacterial therapy in acute ischemic stroke: a randomized controlled trial. PLoS One 3: e2158, 2008.

30. Chamorro A, Horcajada JP, Obach V, Vargas M, et al: The Early Systemic Prophylaxis of Infection After Stroke study: a randomized clinical trial. Stroke 36: 1495-1500, 2005.

31. Lampl Y, Boaz M, Gilad R, et al: Minocycline treatment in acute stroke: an open-label, evaluator-blinded study. Neurology 69: 1404-1410, 2007 